\title{
Investigational Assessment of Modified Performance of Used Tire Concrete Mixtures
}

\author{
Feras Al Adday, Khalil Manaseer, Atallah Alhawarat, Abd Alkareem Idreas \\ Middle East University, Amman, Jordan, falkhalil@meu.edu.jo
}

\begin{abstract}
The need to provide commercial ideas to get rid of the rubber of car tires has become an urgent issue, especially adding to the various construction processes. Adding used tires (UT) to the concrete helps reduce landfill areas and declines the depletion of raw aggregate used in made the concrete mixtures. This research focuses on the study of the effectiveness of the use of UT in concrete mixtures according to the specifications of Jordan Construction, Where a fine aggregates retained on a sieve No. 16 have been replaced with UT. Considering keeping the same volume. It has been adapted replacement ratios of 50 and $100 \%$ of the fine aggregate.

Hardened properties was studied to measure the value of compressive strength (VCS) after 7, 14 and 28 curing days. In addition to determine fresh property (Slump test) to study the efficiency of adding UT on workability. A 18 cubes of $(10 \times 10$ $\mathrm{x} 10 \mathrm{~cm})$ for compressive strength test and a 9 molds $(50 \times 10$ $\mathrm{x} 10 \mathrm{~cm}$ ) for flexural strength test, in addition to a 9 cylinders (15 cm Dia. X $30 \mathrm{~cm}$ height) for tensile strength test, all samples were made at a different percentages of UT $(0 \%, 50 \%$ and $100 \%$ ), at water/cement ratio of 0.60 .

This study concluded that there is no inverse relationship with the increase in the percentage of UT, where the compressive strength at the 100 replacement ratio of UT was greater than $50 \%$, the increase rate was around $19 \%$ at $100 \%$ of UT related to $50 \%$. The results indicated that the workability value was not considerably affected, where the slump value was nearly equal to the various replacement ratios 0 , 50, and 100\%. 90, 100, and $100 \mathrm{~mm}$ respectively. Furthermore, a unit weight of used tires concrete mixes (UTCM) was reduced about $20 \%$ for $100 \%$ replacement and $10 \%$ for $50 \%$ replacement of UT related to normal concrete mixtures ( $0 \%$ UT).
\end{abstract}

Key words: Crumb Rubber, Raw Aggregate, compressive strength, Rubberized concrete.

\section{INTRODUCTION}

Currently, there is a huge amount of used tires (UT) deserted every year in landfills. The amount of used tires is estimated at about 275 billion in the United States and 180 billion annually in the European Union countries. The UT produce an actual ecological hazard, where prohibited disposal of UT is also a great fear [1]. UT can be added as a replaceable portion of coarse or fine aggregate substitutes, and as well as a modifier to Portland cement [2]

Concrete is considered one of the most used materials in the field of civil engineering, but sometimes it suffers from some weakness, such as brittleness and tensile strength. High Concrete strength and an innovative concrete mixes, may be capable to overcome these distresses [3]. Structural work of all types consumes large quantities of raw aggregates in addition to large quantities of destroyed infrastructure materials. Despite this use in construction work, these applications did not bring adequate environmental and economic sustainability [4]. In general, concrete consists of Portland cement, aggregates and water, and some admixture is added to it, is sometimes used to modify concrete properties [5][6][7].

Water is required so as to increase speed a cement hydration and reach to a definite workability when built-up concrete [8]. However, the using of UT with the concrete mixes is capable to increase the impact resistance of concrete and ductility as well may be suggested to be used in conditions where large vibrations should be damped, for example in bridge structures [9][10]. It is used in several road projects [11]. Modified concrete with UT also has the role in the protection of the environment in two ways. First is the conservation of raw aggregates consumption and the second is to reduce the environmental pollution resulting from the breaking of rocks, this is when cutting the UT only and adding it as an alternative to the stone materials [12]. Therefore, Environmental protection is a prerequisite for protecting the human race from the dangers posed to it [13]. In the United States, depletion of raw aggregates is projected to increase to 2.5 billion tons per year in 2020 [14]. UT can be called Crumb Rubber (CR), can be added to the concrete as an alternative to the fine aggregates or coarse aggregates, this concrete product is one of the preserving elements of the environment [15]. CR or UT are used rubber made from heavy truck and automobile scrap tires, which range from $0.075 \mathrm{~mm}$ to a smaller than $4.75 \mathrm{~mm}$ [16]. While the rubber powder 
Feras Al Adday, International Journal of Emerging Trends in Engineering Research, 8(5), May 2020, 1804- 1808

consisting of particles smaller than $0.1 \mathrm{~cm}[10]$.

Various studies have investigated the effects of UT on the hardened, fresh and flexural concrete properties, with the changed replacement ratios and also different sizes of UT. The described results were a decrease or slight increase in the hardened, fresh, densities, and elasticity modulus of concrete by increasing replacement ratios of UT according to the method of replacement or its percentage [2]. Among these studies is the study of R SanthoshKumar and other in 2015, they have replaced the various ratios 15,20 , and $25 \%$ by volume of the fine aggregate to investigate (or the mechanical concrete performance with UT. This research proved that UTCM have higher compressive strength of concrete and improved energy adsorption ability and also has a capability to resist great deformation at $15 \%$ of UT by volume. In addition, they have a higher values of flexural strength. And the lower unit weight is a good result of adding UT [17]. Effects of the confining stress with changed levels and adding of changed percentages of UT on the compressive concrete were studied by Gholampour and other in 2017. Outcomes display that the UTCM decline the compressive strength but greater axial and horizontal distortion abilities than those of the control concrete. The outcomes also demonstration that confining UTCM develops its axial distortion ability and compressive strength considerably. The various proportions $0,6,12$, and $18 \%$ by volume of the sand were replaced in this research [18].

Another research has highlighted the addition of UT as a powder to the concrete. Both Khan and Singh in 2018 replaced $0,5,10$, and $15 \%$ of the fine aggregate by UT. This study concluded that increasing the UT percentage decreased the compressive strength by $18 \%$ and the tensile strength by $43 \%$ at $15 \%$ of UT [19]. A similar study carried out by N. Gerges and other in 2018, regarding UT powder. The fine sand was partly substituted by $5,10,15$, and $20 \%$ by UT powder.

The results indicated that UTCM generally has a lower compressive strength of concrete that can limit its usage in definite construction projects, it has a several desirable performance, such as higher hardiness, higher value of impact resistance and lower a unit weight related to conventional concrete mixes [20].

Abuzaid and others accomplished in 2019 their study in the possibility of filling a circular steel columns with a UT, where the ductility and strength of concrete were studied under axial load. The percentage of UT was $10 \%$ of the percentage of fine materials, the compressive strength of UTCM was about $30 \%$ a smaller amount than that of the conventional concrete. But, the axial load capability of UTCM was $1.4-6.6 \%$ a smaller amount than the conventional mixes. And for the ductility of UTCM, it is better than conventional mixes and can be used in engineering projects subject to vibrations [21].

After reviewing some previous studies and focusing on what a group of researchers reached, the replacement ratios of UT were adopted instead of the sand retained on sieve No. 16, which is the new idea for this research and the replacement ratios were 0,50 and $100 \%$ by the volume. From this principle, this study attempted to produce environmentally friendly and lightweight concrete that can be used in various fields, such as partial partitions in residential buildings or hollow block used in slabs, which can lead to decrease the total dead load and it can reduce the project cost in general.

\section{METHODOLOGY}

To accomplish the objectives of the research, A 18 cubes of $(10 \times 10 \times 10 \mathrm{~cm})$ were prepared with $0 \%, 50 \%$ and $100 \%$ of UT which pass from sieve no. 10 and retained on sieve no. 16, at $\mathrm{W} / \mathrm{C}$ ratio of 0.60 . Hardened properties were examined to determine the compressive strength of UTCM after 7, 14 and 28 curing days. Fresh property (Slump value) was determined to estimate the efficiency of adding UT on concrete workability. Portland cement (type I) brought from Manaseer Cement Industry, UT ranging from 5 to $0.05 \mathrm{~mm}$ from Advance Technical Recycling Material Co. Ltd, Free Zone Area, Al Zarqa, Jordan as revealed in Figure 1. Bulk density of UT is $512 \mathrm{~kg} / \mathrm{m}^{3}$. Set of sieves $\left(1 \frac{1}{2}, 1,3 / 4,1 / 2,3 / 8\right.$ in, No.4 and pan) for coarse aggregate, and set of sieves $(3 / 8$ in, No.4, 10, 16, 30, 40, 100 and pan) for fine aggregate.

Fine and coarse aggregates were designated according to the Jordanian, depend on the climatic and environmental conditions in Jordan [22]. Compressive strength of UTCM was determined in conformity with ASTM C39-05 at 7, 14 and 28 of curing days. Nominal compressive strength was selected $20 \mathrm{MPa}$ at 28 of days curing, where the weights of the concrete components were as follows: Cement was 1.0; Sand 1.5, Coarse aggregate 3.0. Also, nine prisms were prepared to measure the flexural strength, in addition to nine cylindrical samples for tensile strength.

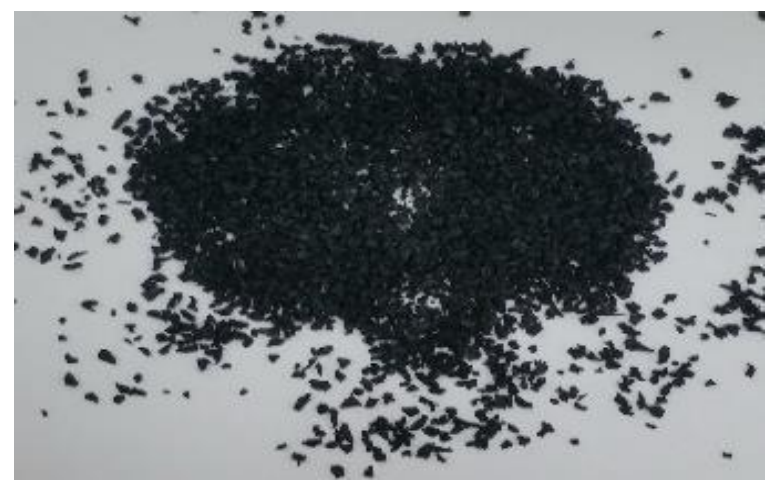

Figure 1: UT size, from 5 to $0.05 \mathrm{~mm}$

\section{RESULTS AND DISCUSSION}

In the last stage of this study, the results were presented with Figures that illustrated the relationships between increasing the percentage of UT with the fresh and hardened properties of concrete.

As is well known, ordinary concrete mixes can be used in many cases with different workability grades in relation to the structural function in which these mixtures are placed [23]. The results indicated that the slump value of UTCM for replacement ratio $100 \%$ and $50 \%$ of UT was equally as shown 
in Figure 2, whereas the slump value for conventional concrete sample was $90 \mathrm{~mm}$. The decrease in slump values due to UT has the absorption rate of water is less than the aggregates that cause decrease the workability. This result leads to the addition of UT does not significantly affect workability of the concrete. The slump values at $50 \%$ or $100 \%$ of UT (UT remaining on the sieve No. 16) after 28 of curing were 100 $\mathrm{mm}$. It is recommended for use in structural sections subject to vibrations such as high ways or it can be used on flat slabs with crashed aggregates consistent with criteria exposed by the reference of Building research establishment [24].

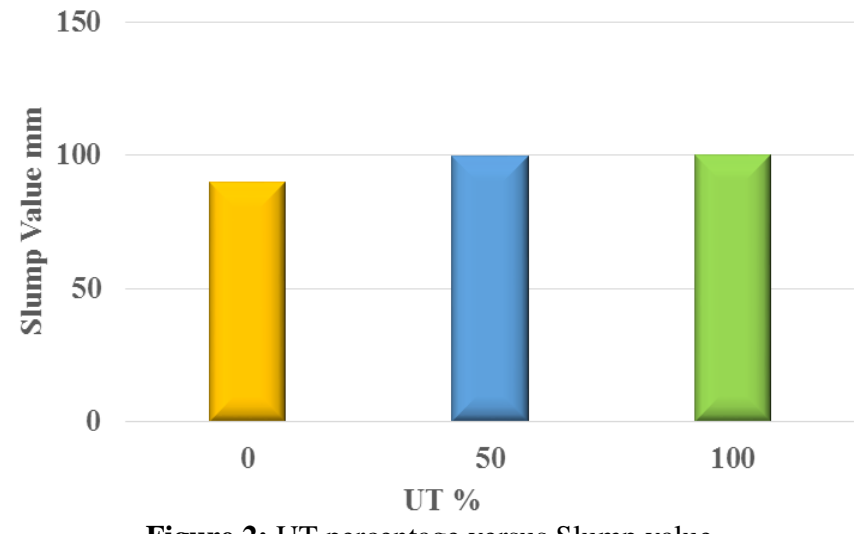

Figure 2: UT percentage versus Slump value

This study concluded that there is no inverse relationship with the increase in the percentage of UT, where the compressive strength at the 100 replacement ratio of UT was greater than $50 \%$ as revealed in the Figure 3, and this result is contrary to all previous studies that confirmed the existence of this inverse relationship, that is, the more the percentage of UT the less compressive strength. The increase rate was around $19 \%$ to replace $100 \%$ UT, which showed that the UT had an important effects on the VCS, this behavior might be as a result of the lower absorption of water of UT related to the raw aggregates. The VCS at 28 curing days was the higher value in comparison with 7 and 14 curing days.

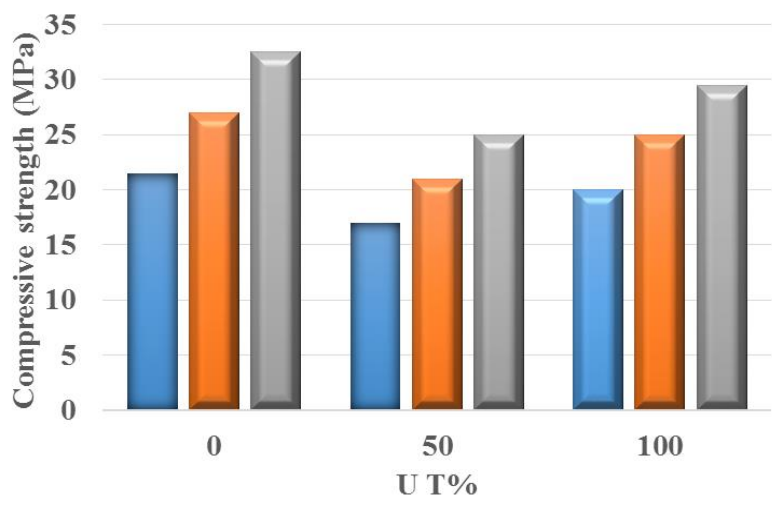

Figure 3: UT percentage versus compressive strength
Determination of the flexural strength is important in a well-designed process of reinforced concrete, this is in order to properly assess the relationship between compressive strength and tensile strength, especially so with regard to deformation and cracking in concrete [25]. As shown in Figure 4, the flexural strength of concrete were 2.7 MPa for conventional mix, 2.4MPa for UTCM with $100 \%$ of UT, and $2.3 \mathrm{MPa}$ for UTCM with 50 . Based on the results, it was confirmed that the VCS at 100 of the UT is greater than $50 \%$ of UT.

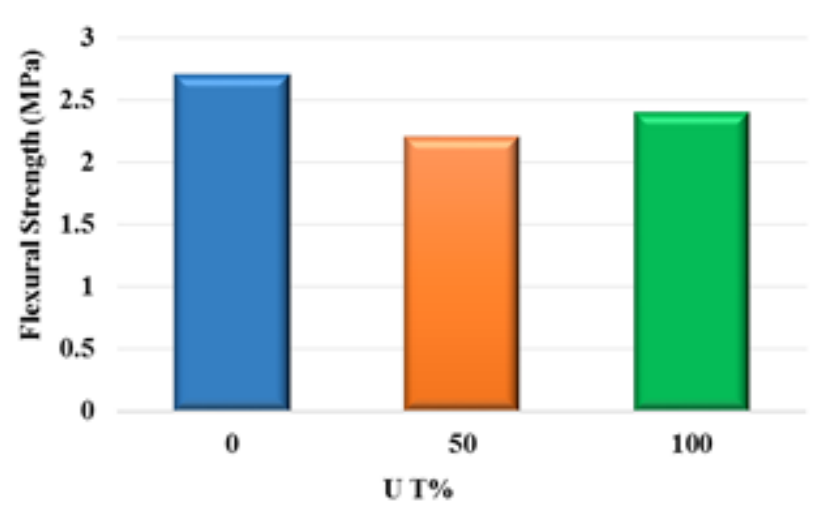

Figure 4: UT percentage versus flexural strength

Figure 5 shows that the tensile strength value at $100 \%$ of UT lower than $50 \%$ of UT after 28 curing age. This may be because of the reduction of bonding between the UT surfaces and cement binder in new concrete which constitutes a relatively weak area compared to the natural aggregates during the concrete tension process.

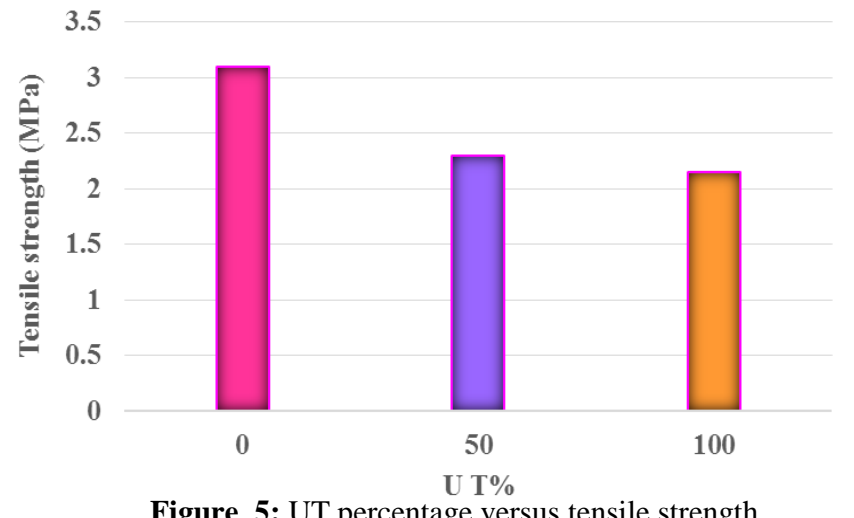

4. CONCLUSION

Based on the set of results reached in this research, it was found that replacing the fine aggregates by UT gives positive results, where the fine aggregate were retained on sieve No. 16, while the replacement rate was 50 and $100 \%$ UT.

One of these positive results is a $20 \%$ reduction in a unit weight of used tires concrete mixes (UTCM) for 100\% replacement and $10 \%$ for $50 \%$ replacement of UT related to normal concrete mixtures ( $0 \%$ UT). This study concluded that there is no inverse relationship with the increase in the percentage of UT, where the compressive strength at the 100 replacement ratio of UT was greater than $50 \%$, the increase 
Feras Al Adday, International Journal of Emerging Trends in Engineering Research, 8(5), May 2020, 1804- 1808

rate was around $19 \%$ at $100 \%$ of UT related to $50 \%$.

The results indicated that the workability value was not considerably affected, where the slump value was nearly equal to the various replacement ratios 0,50 , and $100 \% .90,100$, and $100 \mathrm{~mm}$ respectively. Furthermore, a unit weight of used tires concrete mixes (UTCM) was reduced about $20 \%$ for $100 \%$ replacement and $10 \%$ for $50 \%$ replacement of UT related to normal concrete mixtures $(0 \% \mathrm{UT})$. It is recommended for use in structural sections subject to vibrations such as a surface layer on the road.

\section{ACKNOWLEDGMENT}

The author are grateful to the Middle East University, Amman, Jordan for the financial support granted to cover the publication fee of this research article.

\section{REFERENCES}

1. Audrius Grinys, Algirdas Augonis, Mindaugas Daukšys, Darius Pupeikis, 2020. Mechanical properties and durability of rubberized and SBR latex modified rubberized concrete. Construction and Building Materials $\quad 248 \quad$ (2020) 118584 https://doi.org/10.1016/j.conbuildmat.2020.118584.

2. Abu Bakar Nabilah , Noaman Mohammed Ridha Noaman, Noor Azline Mohd. Nasir, andNor Azizi Safiee, 2017. Experimental evaluation of flexural behaviour of rubberized concrete Beam. Asian Journal of Civil Engineering.

https://doi.org/10.1007/s42107-019-00159-5.

3. Mohamadreza Shafieifar, Mahsa Farzad, Atorod Azizinamini, 2017. Experimental and numerical study on mechanical properties of Ultra High Performance Concrete (UHPC). Construction and Building Materials 156 (2017) 402-411. http://dx.doi.org/10.1016/j.conbuildmat.2017.08.170.

4. M. C. Limbachiya, T. Leelawat and R. K. Dhir, 2000. Use of recycled concrete aggregate in high-strength. Materials and Structures/Mat\&iaux et Constructions, Vol. 33, November 2000, pp 574-580. https://doi.org/10.1007/BF02480538

5. Salahaldein Alsadey, 2013. Effects of Super Plasticizing and Retarding Admixtures on Properties of Concrete. International Conference on Innovations in Engineering and Technology (ICIET'2013) Dec. 25-26, 2013 Bangkok (Thailand).

6. Sulagno Banerjee and Jessy Rooby, 2019. Strength Properties of Tyre Rubber Concrete. International Journal of Recent Technology and Engineering (IJRTE). DOI:10.35940/ijrte.D8902.118419.

7. Aymen Awad, 2020. Guidelines for Civil Structures Demolition Method Selection to Enhance Environmental Protection. International Journal of Emerging Trends in Engineering Research, Volume 8. No. 2, https://doi.org/10.30534/ijeter/2020/11822020.

8. Young Je, Woo, Hwa Sung, Ryu, Sang Hwa, Jung, and Sung Tae, Chae., 2008. A Study on the Addition of
Extra Water Which Affects the Durability Degradation of Concrete. International Conference on Durability of Building Materials and Components, Istanbul - Turkey] may 11-14th, 2008.

9. Mohamad Syamir Senin, Shahiron Shahidan, , Siti Radziah Abdullah, Nickholas Anting Guntor, Alif Syazani Leman, 2017. A review on the suitability of rubberized concrete for concrete bridge decks. IOP Conf. Series: Materials Science and Engineering 271 (2017) 012074 doi:10.1088/1757-899X/271/1/012074.

10. Camille A. Issa, Nagib N. Gerges, Samer Fawaz. 2017. Mechanical and Dynamical Properties of Rubber Concrete. Journal of Building Material and Structural Engineering (JBMSE). Vol 1, Issue 1, July 2017.

11. Y. Kamala Raju, N. Harish Kumar, 2019. Strength Performance of Crumb Rubber Concrete. International Journal for Research in Applied Science \& Engineering Technology (IJRASET). Volume 7 Issue V, May 2019-Available at www.ijraset.com. https://doi.org/10.22214/ijraset.2019.5334

12. Essam Eltayeb, Xing Ma, Yan Zhuge and Osama Youssf. 2020. Fresh and Hardened Properties of Innovative Foamed-Rubberized Concrete. Springer Nature Singapore Pte Ltd. 2020. https://doi.org/10.1007/978-981-13-7603-0_4.

13. Nik. D. Oikonomou. Recycled concrete ggregates. Cement \& Concrete Composites 27, 2005, pp.315-318. doi:10.1016/j.cemconcomp.2004.02.020.

14. Feras Al Adday, Aymen Awad, 2019. Pre-Wetting of Recycled Concrete as Alternative of Chemical, Natural and Industrial Waste Additives. International Journal of Innovative Technology and Exploring Engineering (IJITEE). DOI: 10.35940/ijitee.L3166.1081219.

15. Thong M. Pham, Wensu Chen, Abdul M. Khan, Hong Hao, Mohamed Elchalakani, Tung M. Tran. Dynamic Compressive Properties of Lightweight Rubberized Concrete. https://www.researchgate.net/publication/337618341.

16. Suraj Shah, Saurav Shrestha,Sujan Maharjan, Nishma Karki, and Rameswor Shrestha, 2019. Evaluation of performance of rubber concrete. $\sigma^{\text {th }} I O E$ graduate conference may 2019.

17. R SanthoshKumar, S Arulkesavan, N Manodeepan, S Prabhavathi, K Manikandan, 2015. An Experimental Investigation on Rubberized Concrete. IJIRST -International Journal for Innovative Research in Science \& Technology| Volume 2 | Issue 07 | December 2015.

18. Aliakbar Gholampour, Togay Ozbakkaloglu, and Reza Hassanli, 2017. Rubberized concrete under confinement.

https://www.researchgate.net/publication/318106310

19. Sabir Khan and Akanksha Singh, 2018. Behavior of Crumb Rubber Concrete. International Journal of Research in Engineering, Volume 08 Issue 2, February 2018, Page 86-92. 
Feras Al Adday, International Journal of Emerging Trends in Engineering Research, 8(5), May 2020, 1804- 1808

20. Najib N. Gerges, Camille A. Issab, Samer A. Fawaz, 2018. Rubber concrete: Mechanical and dynamical properties. Case Studies in Construction Materials xxx (2018). e00184. https://doi.org/10.1016/j.cscm.2018.e00184.

21. Abuzaid O, Nabilah.A.B, Safiee N.A. and Noor Azline M.N, 2019. Rubberized concrete filled steel tube. IOP Conf. Series: Earth and Environmental Science 357 (2019) 012014. doi:10.1088/1755-1315/357/1/012014.

22. Aymen Awad, Firas Al Bajari and Feras Al Adday, 2019. A Case Study on Rainwater Harvesting and Reuse in Jordan. International Journal of Emerging Trends in Engineering Research Volume 7. No. 11, https://doi.org/10.30534/ijeter/2019/017112019.

23. Feras Al Adday, Aymen Awad, Rawan Aleghnimat, Hamzeh Bassam and Amer Khater, 2019. Fresh and hardened properties of recycled concrete aggregate modified by iron powder and silica. International Journal of GEOMATE, Jan. 2019, Vol.16, Issue 53, pp.222 - 230. https://doi.org/10.21660/2019.53.96609.

24. S. K. Duggal. Building Materials. Third revised edition, New Age InternationalPublishers, 2009.

25. Augustine U. Elinwa and Nasir Kabir, 2019. Flexural Strength and Compressive Strength Relations of Hospital Waste Ash-Concrete SSRN Electronic Journal. DOI:10.2139/ssrn.3309506 